\title{
Changing Horses
}

\author{
Marvin L. Birnbaum, MD, PhD
}

The use of travelling is to regulate imagination by reality, and instead of thinking bow things may be, to see them as they are. Samuel Johnson, Writings,

Volume vi, p 31.

If you will be a traveller, have always the eyes of a falcon, the ears of an ass, the face of an ape, the mouth of a bog, the shoulder of a camel, the legs of a stag, and see that you never want two bags very full, that is one of patience and anotber of money. John Florio, Second Frutes,

Fo. 93 (1591)
Prehospital and Disaster Medicine (PDM) is about to begin its twelfth volume and will extend its journey to the Information Superhighway. In the relatively short time since its rebirth, we have traveled a long distance. We have built a strong vehicle for our travels. We have helped to create science where there was none. We have expanded the definitions for our science to include methodologies that have been outside the traditional concepts of medical research. We have impacted the practice of the new and now rapidly evolving medical fields of Disaster Medicine and Prehospital Emergency Care. We fill an important niche. As evidenced by the rapidly increasing number of manuscripts submitted from and the acquisition of subscriptions from all corners of the world, it has become a truly international vehicle. We have met all of the initial objectives established by our sponsoring organizations. ${ }^{1}$ Progress has been rapid and will continue in the face of two changes which occurred with the completion of the last issue (Volume 11:4): 1) a new publisher; and 2) one of the sponsoring organizations (NAEMSP) has departed PDM to begin publication of a new journal focused on out-of-hospital emergency medical care.

In many ways, we are sad to leave the stables of Jems Communications. From its beginnings as the publisher of the Journal of Emergency Medical Services (JEMS), Jems has been committed to the enhancement of medical care in the new arena of prehospital emergency care and the care provided to victims of disaster. Without the vision and resources provided by Jems, PDM may never have been reborn or evolved to its current state. It was the encouragement and understanding of Keith Griffiths and the belief and faith of Jim Page that provided the horses to propel PDM down the road. It was moved by the commitment, dedication, and talents of so many individuals that have formed the soul of Jems. I am thankful for the knowledge, competence, patience, and drive of Dana Bies: without all that she brought to the early production, PDM could not have become the vehicle into which it has evolved; and for the artistic sensitivity of Bob Schmidt that resulted in the initial overall design of the Journal; and for the persistence and organizational skills Janene Long-Forman, for it is she of who has continued to pull all of the elements of each issue together; and for the tenacity of Gail Williams in production, for she kept us moving over the rough roads; and for Tracy Michael whose commitment, understanding, and belief in the product helped us past the uneven road onto a smooth course filled with gentle understanding and cooperation. These are but a few of the many people who have been responsible for the ongoing production and maturation of PDM. Every reader, each contributor, all members of the sponsoring organizations, and the entire editorial staff from Tracy Will, Elizabeth Chapin, and Kathleen Adler to Donna Schaan owe much to all of the staff of Jems for providing the power to move this vehicle to where we are today. We all thank you for all that you have given to this effort and we will miss galloping with you into the sunrise.

The vision and energy of Mic Gunderson and Mike King who began the Tampa Bay EMS Journal were instrumental in conceptualization of the structure of PDM. It was the need of the National Association of Emergency Medical Services Physicians (NAEMSP) to develop a medical journal to facilitate the development of the rapidly evolving field of prehospital emergency medical services with the leadership of Paul Pepe and Paul Paris, that provided the impetus 
for PDM. This, coupled with the experience of the World Association for Emergency and Disaster Medicine (now WADEM) provided the lumber and hardware necessary to enhance the original wagon begun previously as the Journal of the World Association for Emergency and Disaster Medicine. Combined with the frame and wheels provided by WADEM and editors Peter Safar and RA Cowley, we were able, together, to build a solid wagon to carry the goods that the authors provided. The vehicle that resulted has helped NAEMSP and WADEM grow and prosper. But, NAEMSP has decided the vehicle no longer meets its needs and is hopping off this accelerating vehicle to develop a new wagon. I personally thank NAEMSP for its tolerance. Especially, I am grateful to Kathleen StageKern for her support and guidance. Katie provided the heart for NAEMSP.

But this vehicle continues onward with the ongoing support and guidance of the World Association for Disaster and Emergency Medicine and the international community concerned with emergency medical care and disaster medicine. It will continue to streamline and gain speed. It will be powered by a new publisher with a profound interest and commitment to make PDM a stronger and more cutting-edge vehicle with the ability to extend its journey into new and unknown places. Shaped by a broader and stronger international Editorial Board, it will travel down an improved road-a road built for ease of access with a vehicle committed to greater speed in moving products from submission to publication. It will serve the needs of many individuals, cultures, and organizations. Its form will be versatile and user friendly.

We have come a long distance together. During our travels, we have experienced much. And each of us has grown and benefited from these joint experiences. We gloried when the road was smooth and straight and survived the journey over difficult terrain. During our journey, we have not followed, but instead have forged new roads where there were none. So far, it has been a good journey, but the journey only has begun.

It always is sad when fellow travelers part. But our journey continues and our vehicle is strong. There remain many places to go, and the road is wide and clear. There are few if any other vehicles on our road. We continue on our way. We are traveling on a Superhighway.

The fool wanders, the wise man travels.

Thomas Fuller, Gnomologia, no. 4540

\section{Footnote}

1. Birnbaum ML: Editor's Welcome. Prehospital and Disaster Medicine 1989;4:7-8. 